\title{
Assessment of Patient Satisfaction with On-Site Point- of-Care Hemoglobin A1c Testing: An Observational Study
}

\author{
Ayman A. Al Hayek (D) · Abdulghani H. Al-Saeed · Wael M. Alzahrani •
}

Mohamed A. Al Dawish (D)

Received: June 15, 2021 / Accepted: July 20, 2021 / Published online: August 7, 2021

(C) The Author(s) 2021

\begin{abstract}
Introduction: Poor glycemic control is a serious challenge in successful diabetes management. Given the low adherence and compliance with HbA1c testing frequency and the corresponding delay in the appropriate medication adjustment, point-of-care testing (POCT) for HbA1c provides an opportunity for better control of diabetes and higher patient satisfaction. The data with this regard are limited in Saudi Arabia. Therefore, we aimed to assess the level of patient satisfaction associated with the POCT service implementation for HbA1c and evaluate the differences between the number of requested and conducted
\end{abstract}

Supplementary Information The online version contains supplementary material available at https:// doi.org/10.1007/s13300-021-01126-7.

A. A. Al Hayek $(\bowtie)$ A. H. Al-Saeed

W. M. Alzahrani · M. A. Al Dawish

Department of Endocrinology and Diabetes,

Diabetes Treatment Center, Prince Sultan Military

Medical City, P.O. Box 7897, Riyadh 11159, Saudi

Arabia

e-mail: ayman.alhayek@yahoo.com

A. H. Al-Saeed

e-mail: ahalsaeed@psmmc.med.sa

W. M. Alzahrani

e-mail: wael_mz@hotmail.com

M. A. Al Dawish

e-mail: maldawish@psmmc.med.sa
HbA1c tests before and after POCT implementation and its effect on glycemic control in Saudi clinical practice.

Methods: We conducted a single-center ambispective descriptive cohort study in Riyadh, Saudi Arabia. This study had two phases: the retrospective phase (January 2017 to December 2017) and the prospective phase (January 2018 to December 2018). Patient satisfaction was assessed using the patient satisfaction questionnaire short form (PSQ-18) and on-site HbA1c point-of-care testing (HbA1c-POCT) satisfaction questionnaire.

Results: This study included 75 patients with diabetes (37\% type $1,63 \%$ type 2 ) with a mean age of $44.35( \pm 17.97)$ years. The adherence to physician recommendations for HbA1c testing frequency increased from $24 \%$ to $85 \%$ (before and after POCT implementation, respectively). High levels of satisfaction across seven dimensions of PSQ-18 (77-88\%) were reported towards the provided healthcare service after POCT implementation. Furthermore, a high level of agreement on the statements of the on-site HbA1c-POCT satisfaction questionnaire was also observed. Finally, the mean HbA1c level has significantly improved after POCT implementation compared to the traditional HbA1c laboratory testing before POCT implementation $[8.34 \pm 0.67$ and $8.06 \pm 0.62$, respectively, $p<0.001$ ).

Conclusion: HbA1c testing at POCT improved adherence to recommendations for $\mathrm{HbA} 1 \mathrm{c}$ testing frequency for better glycemic control and higher 
patient satisfaction. POCT reduces turnaround time, improves glycemic control, and facilitates the decision-making process. HbA1c measurement with POC devices is recommended to be implemented in diabetes treatment centers. All of the described benefits of POCT come together to make $\mathrm{HbA1c}$ testing the most common procedure for diabetes management at the point of care.

Keywords: Diabetes; Point of care; POCT; PSQ18; HbA1c; Saudi Arabia

\section{Key Summary Points}

\section{Why carry out this study?}

Data regarding the value of point-of-care testing (POCT) for HbA1c in Saudi Arabia are scanty. Therefore, we conducted this study to assess the level of patient satisfaction with the POCT for HbA1c.

As a result of the notable low adherence and compliance with $\mathrm{HbA1c}$ testing frequency in clinical practice, we evaluated the differences between the number of requested and conducted HbA1c tests before and after POCT for HbA1c implementation to determine the level of adherence to HbA1c testing.

Poor glycemic control is a serious challenge in successful diabetes management. Therefore, we assessed the value of implementing the POCT for HbA1c in clinical practice to improve the level of glycemic control.

\section{What was learned from the study?}

In comparison to traditional $\mathrm{HbA1c}$ laboratory testing, POCT implementation has significantly improved glycemic control.

The POCT service implementation was associated with an enhanced level of adherence to physician recommendations for HbA1c testing.

We observed a high level of agreement on the on-site HbA1c-POCT satisfaction questionnaire's statements.

\section{INTRODUCTION}

Diabetes mellitus (DM) is one of the top public health challenges that drive a major burden on global public health [1]. The disease prevalence has risen considerably in the vast majority of both developed and developing countries over the past decades [2-4]. According to the International Diabetes Federation (IDF), DM affected about 463 million adult individuals around the world in 2019. This figure will increase to 548 million by 2045 if no significant interventions are implemented to prevent or control the disease [5]. With regards to the Middle East and North Africa (MENA) region, the prevalence of diabetes in adults was estimated to be 54.8 million people as per the IDF 2019 and might be increased to 107.6 million by 2045 [5]. The total prevalence of DM in the Kingdom of Saudi Arabia (KSA) was $14.4 \%$ according to the World Health Organization (WHO) diabetes country profile [6].

Monitoring the blood glucose level assessed with the glycosylated hemoglobin (HbA1c) test usually takes place in primary care clinics and requires multiple visits by the patient [7]. Furthermore, the delay in communicating HbA1c test results, due to the time consumed between visits, can delay important modification or intensification of the treatment plan and reduce patient adherence [8]. On a real-world basis, compliance with HbA1c test frequency is very limited and can be observed in only $7 \%$ of patients with diabetes [9]. As reported by NHANES (National Health and Nutrition Examination Survey), only $63.7 \%$ of patients with diabetes achieve their goal for HbA1c [10].

Previously, insulin, metformin, and sulfonylureas were the only available treatment for diabetes, followed by thiazolidinones and acarbose in the late 1990s. In the twenty first century, new antidiabetic agents have been launched, including sodium-glucose cotransporter 2 (SGLT2) inhibitors, glucagon-like peptide 1 (GLP-1) receptor agonists, dipeptidyl peptidase 4 (DPP4) inhibitors, and colesevelam. The American Diabetes Association and the European Association for the Study of Diabetes (ADA/EASD) revised their type 2 diabetes care 
guidelines in 2015. Following the use of metformin as the first-line treatment, they recommend that any of the other therapeutic classes, including basal insulin, could be the second line, and any other combination could be the third or fourth line, while injectable therapy was highlighted as the fourth line in addition to the preceding agent [11]. On the other hand, multiple daily insulin injections utilizing bolus insulin or continuous subcutaneous infusion are the recommended therapy for type 1 diabetes $[12,13]$.

High HbA1c levels observed in $50-60 \%$ of patients with diabetes are attributable to either not receiving adequate care plans or non-adherence to their plan. Furthermore, diabetes management failure following treatment intensification is mainly caused by delayed treatment escalation [14]. Eventually, addressing poor glycemic control is seen as a serious challenge in successful diabetes management [8].

In 2004, many focus groups and in-depth interviews by Brown et al. were conducted with key stakeholders and health professionals and recommended introducing the near-patient point-of-care testing (POCT) devices to clinicians, nurses, and diabetes educators for better glycemic control [15]. POCT could be defined as "testing at or near the site of patient care wherever that medical care is needed for which the result is available without reference to a laboratory and perhaps rapidly enough to affect patient management" [16]. In 2021, the ADA standards of medical care recommended the use of POCT for HbA1c in order to provide patients with well-timed treatment changes [7]. A wide range of instruments can be used in POCT, including benchtop or handheld devices to provide rapid results within only a few minutes [17]. This approach of providing immediate feedback at the site of patient care can improve the traditional fragmented process of monitoring patients over multiple visits [18]. In addition, POCT allows the opportunity for immediate face-to-face discussion between the healthcare provider and the patient, along with permitting any necessary treatment changes to take place within a single consultation. POCT for $\mathrm{HbA1c}$ was shown to improve treatment outcomes and diabetes management compared to the traditional HbA1c laboratory testing $[9,10,16]$.

Patient satisfaction with POCT for HbA1c is an essential factor in the assessment process of this technology to be expanded in the medical practice $[19,20]$. Patient satisfaction is a costeffective and straightforward approach to evaluating healthcare effectiveness because it represents the continuous enhancement of the healthcare system [21]. Data from the literature suggest that the implementation of POCT for HbA1c was associated with reducing turnaround time, improving the patient glycemic index, providing timely test results along with treatment modifications, facilitating the decision-making process, avoiding multiple patient visits, and allowing for better discussion between patient and provider; altogether, it may contribute considerably to the patient level of satisfaction and overall impression $[17,19,22-24]$

We conducted this study to assess the level of satisfaction associated with the implementation of POC for HbA1c testing in large tertiary care hospitals in Saudi Arabia, to evaluate the patients' adherence to physician recommendations for HbA1c testing frequency before and after the POCT implementation, and lastly to determine the common reasons for not performing traditional $\mathrm{HbA} 1 \mathrm{c}$ tests.

\section{METHODS}

\section{Study Design and Procedures}

We conducted a single-center ambispective descriptive cohort study at the Department of Endocrinology and Diabetes, Diabetes Treatment Center, Prince Sultan Military Medical City (PSMMC), Riyadh. Patients with diabetes who attended our center from January 2017 to December 2018 were eligible for participation in this study. The study protocol was approved by the Research and Ethics Committee of PSMMC (IRB approval No. 1486). After we clearly explained the objectives and research methodology, all participants provided oral and written informed consent before completing the study 
measurement. For patients 18 years of age or younger, verbal consent from the patients and written informed consent from their parents/caregivers were obtained. Our study was performed in accordance with the Helsinki Declaration of 1964, and its later amendments.

This study was part of the PSMMC local experience to determine the clinical effectiveness and patient satisfaction of on-site POCT for HbA1c testing using the Cobas b 101 HbA1c analyzer, a point-of-care device manufactured by Roche. The Cobas b 101 device is a reliable POC HbA1c analyzer with good correlation with the laboratory method and a high rate of precision [25].

In the first phase of the study, January 2017 to December 2017, a retrospective data collection of the actual number of HbA1c tests performed in the laboratory and the average of $\mathrm{HbA} 1 \mathrm{c} \%$ were obtained from medical charts to be compared with the same parameters following implementation of POCT prospectively during the period from January to December 2018 (second phase). The patient satisfaction with on-site $\mathrm{HbA} 1 \mathrm{c} \%$ testing was also monitored using an anonymous POCT patient satisfaction survey and patient satisfaction questionnaire short form (PSQ-18).

\section{Study Population}

We considered any patient attending the POCT service at PSMMC. All patients who required HbA1c testing for DM monitoring as deemed appropriate by their treating physician during the retrospective phase of the study (January 2018 to December 2018) were eligible to receive HbA1c POCT if they (1) agreed to participate in the study and sign the informed consent form and (2) had retrospective data for the last 1 year before implementing the POCT. A total of 75 patients who received POCT were given an anonymous POCT patient satisfaction survey and patient satisfaction questionnaire short form (PSQ-18) at the end of phase 2 of the study.

\section{Study Objectives and Data Collection}

The primary objectives of this study were to evaluate differences between the number of requested $\mathrm{HbA1c}$ tests before the implementation of on-site HbA1c service (January 2017 to December 2017) and the actual number of HbA1c tests performed in the laboratory, to be compared to the same parameters following implementation of this service (January to December 2018) and its impact on POCT patient-reported satisfaction, and patient satisfaction questionnaire. Secondary objectives were (1) to determine the impact of the place of residence, type of DM, and gender on the patient satisfaction questionnaire after implementing the POCT, and (2) to collect the most common reasons for not performing traditional HbA1c testing in the laboratory before implementing the POCT.

To achieve these objectives, the following data were collected:

(1) Baseline information including sociodemographic and clinical characteristics (age, gender, place of residence, treatment modality, and DM duration.

(2) Retrospective data collection: clinic schedules and visit records were retrospectively reviewed from January to December 2017 (before POCT implementation) to identify the number of requested $\mathrm{HbA} 1 \mathrm{c}$ tests and the average $\mathrm{HbA} 1 \mathrm{c} \%$ compared to the number of performed HbA1c tests for each patient.

(3) Prospective data collection: clinic schedules and visit records were prospectively monitored from January to December 2018 (after POCT implementation) to identify the number of requested $\mathrm{HbA} 1 \mathrm{c}$ tests and the average $\mathrm{HbA} 1 \mathrm{c} \%$ compared to the number of performed HbA1c tests for the same patient. Satisfaction was measured at the end of this period using the level of agreement with various statements in the patient satisfaction questionnaire (PSQ-18) and the on-site point-of-care testing satisfaction questionnaire. 


\section{Assessment of Patient Satisfaction}

Satisfaction with HbA1c on-site POCT was measured using the patient satisfaction questionnaire short form (PSQ-18) [26]. The PSQ-18 assesses 18 items probing seven dimensions of patient satisfaction, including general satisfaction ( 2 items), technical quality (4 items), interpersonal manner ( 2 items), communication ( 2 items), time spent with the doctor (2 items), accessibility and convenience (4 items), and financial aspects ( 2 items). The highest satisfaction with medical care receives a score of 5 , and the lowest satisfaction with medical care receives a score of 1 . The questionnaire is available for free in the public domain [27]. The full instructions for using the PSQ-18 is presented are Table S1 in the supplementary material.

In addition, the on-site HbA1c point-of-care testing (HbA1c-POCT) satisfaction questionnaire [16] was used to assess the patient satisfaction towards the POCT implementation [20]. This questionnaire includes eight statements; these addressed six categories: collection process, confidence in the process, confidence in the result, convenience, cost, and disease management. Participants were asked to indicate how strongly they agreed/disagreed with the survey statements concerning their satisfaction with aspects of the on-site Cobas b $101 \mathrm{HbA1c}$ Analyzer point-of-care testing using a visual analogue scale as presented in Table S2 in the supplementary material.

\section{Statistical Analysis}

The data were analyzed using SPSS version 25 software. All categorical variables are presented in frequency and percentage, whereas the continuous variables are presented with descriptive statistics (median, mean, SD, and IQR). Data normality was tested by the Kolmogorov-Smirnov test. To compare the baseline data and the outcome variables on a continuous scale, paired $t$ test or Wilcoxon signed ranks test were used as appropriate for paired data comparisons. However, independent $t$ test or the Mann-Whitney test was used for independent data comparison as appropriate. To compare the categorical variables, chi-square was used. An alpha level below 0.05 was used to indicate statistical significance. Sample power estimation was performed using $\mathrm{G}^{*}$ Power 3.1.9.2. With 75 patients, the study was able to detect an effect size of 0.34 standard deviations for the paired comparison of the primary endpoint using the Wilcoxon signed ranks test with a power of $81 \%$ and alpha error level of $5 \%$.

\section{RESULTS}

\section{Sociodemographic Characteristics}

Out of 87 invited patients who fulfilled the eligibility criteria, only 75 patients with a mean

Table 1 Summary of patients' characteristics

\begin{tabular}{|c|c|}
\hline Variables & Values $(n=75)$ \\
\hline \multicolumn{2}{|l|}{ Age, years } \\
\hline Mean $( \pm$ SD $)$ & $44.35( \pm 17.97)$ \\
\hline Median (range) & $45(15-81)$ \\
\hline Male gender, $n(\%)$ & $39(52 \%)$ \\
\hline \multicolumn{2}{|l|}{ Geographic region $^{a}$} \\
\hline Riyadh & $52(69.3 \%)$ \\
\hline Outside Riyadh & $19(25.3 \%)$ \\
\hline \multicolumn{2}{|l|}{ Type of DM } \\
\hline T1DM & $28(37.3 \%)$ \\
\hline T2DM & $47(62.7 \%)$ \\
\hline \multicolumn{2}{|l|}{ Treatment } \\
\hline Insulin & $22(29.3 \%)$ \\
\hline Insulin pump & $11(14.7 \%)$ \\
\hline OHA & $11(14.7 \%)$ \\
\hline OHA and insulin & $31(41.3 \%)$ \\
\hline \multicolumn{2}{|l|}{ DM duration } \\
\hline Mean $( \pm S D)$ & $12.59( \pm 9.16)$ \\
\hline Median (range) & $10(2-42)$ \\
\hline \multicolumn{2}{|c|}{$\begin{array}{l}D M \text { diabetes mellitus, } O H A \text { oral hypoglycemic agents, } \\
T 1 D M \text { type } 1 \text { diabetes mellitus, } T 2 D M \text { type } 2 \text { diabetes } \\
\text { mellitus } \\
\text { a Four patients are missing }\end{array}$} \\
\hline
\end{tabular}


age of $44.35( \pm 17.97)$ years responded and agreed to participate in the study. The demographic characteristics of the study population are shown in Table 1 . Type 1 and type 2 diabetes represented $37 \%$ and $63 \%$ of the included patients, respectively.

\section{On-Site POCT Service and Glycemic Control}

During the period from January 2017 to December 2017 (before implementing the HbA1c on-site POCT service), the median number of performed HbA1c tests at the laboratory was significantly lower than that requested [median (range) of 2 (1-4) and 3 (1-5), respectively, $p<0.001]$. During the period from January 2018 to December 2018 (after implementing the HbA1c on-site POCT service), the results revealed no significant difference between the number of $\mathrm{HbA} 1 \mathrm{c}$ tests performed at the POCT or laboratory and that requested [median (range) of 3 (1-6) and 3 (1-5), respectively, $p=0.233$ ] as presented in Table 2 . In addition, the number of HbA1c tests performed in the lab and/or on-site is more than the number of requested tests in 22 (29\%) patients after implementing the POCT service.

High level of adherence to guideline-compliant HbA1c testing frequency by physicians or diabetic educators increased from $24 \%$
(12 months before POCT implementation) to 85\% (12 months after POCT implementation).

Regarding glycemic control, the mean HbA1c level has significantly improved after implementing the on-site POCT service compared to the traditional laboratory test [mean $( \pm \mathrm{SD})$ of $8.34( \pm 0.67)$ and $8.06( \pm 0.62)$, respectively, $p<0.001)$. However, there was no difference between type 1 and type 2 diabetes in the mean change in HbA1c $[0.33( \pm 0.32)$ and $0.24( \pm 0.3)$, respectively, $p=0.24]$.

Patients reported that the most common reasons for not performing the requested HbA1c tests before the on-site POCT service implementation are difficulties in handling absence from school/work (56\%), inconvenience associated with revisits $(45.3 \%)$, and the additional costs of travel (44\%) as seen in Fig. 1.

\section{Patient Satisfaction}

Table 3 summarizes the level of satisfaction among the patients with diabetes by each item of PSQ-18. In the domain of general satisfaction, about $86.7 \%$ of patients were satisfied and reported that the medical care they have been receiving was perfect. Regarding the technical quality items, most patients $(88 \%)$ reported that doctors were careful to provide complete medical care and check everything when treating and examining them. Furthermore, about

Table 2 Number of HbA1c tests requested and performed before and after the POCT implementation

\begin{tabular}{|c|c|c|c|c|c|c|}
\hline & \multicolumn{2}{|c|}{ Number of HbA1c\% tests ${ }^{a}$} & \multicolumn{4}{|l|}{ Comparison } \\
\hline & Requested & Performed $^{\mathbf{b}}$ & $\overline{\text { Negative ranks }}{ }^{c}$ & Positive ranks $^{d}$ & Ties $^{\mathrm{e}}$ & $p$ value $^{\mathrm{f}}$ \\
\hline January 2017-Dec 2017 & $3(1-5)$ & $2(1-4)$ & 57 & 0 & 18 & $<0.001$ \\
\hline \multicolumn{7}{|l|}{ [Before POCT] } \\
\hline January 2018-Dec 2018 & $3(1-5)$ & $3(1-6)$ & 11 & 22 & 42 & 0.233 \\
\hline [After POCT] & & & & & & \\
\hline
\end{tabular}

a Date presented as median (range)

b HbAlc test performed on-site [median and range of $2(1-4)$ ] and in lab [median and range of 2 (0-4)]. For some patients $(n=22)$, the number of HbAlc tests performed in the lab and on-site is more than the number of requested HbAlc tests

c Negative ranks: number of $\mathrm{HbA1c} \%$ tests performed $<$ number requested

d Positive ranks: number of $\mathrm{HbAlc} \%$ tests performed $>$ number requested

e Ties: number of $\mathrm{HbAlc} \%$ tests performed $=$ number requested

f $P$ value of Wilcoxon signed rank test 


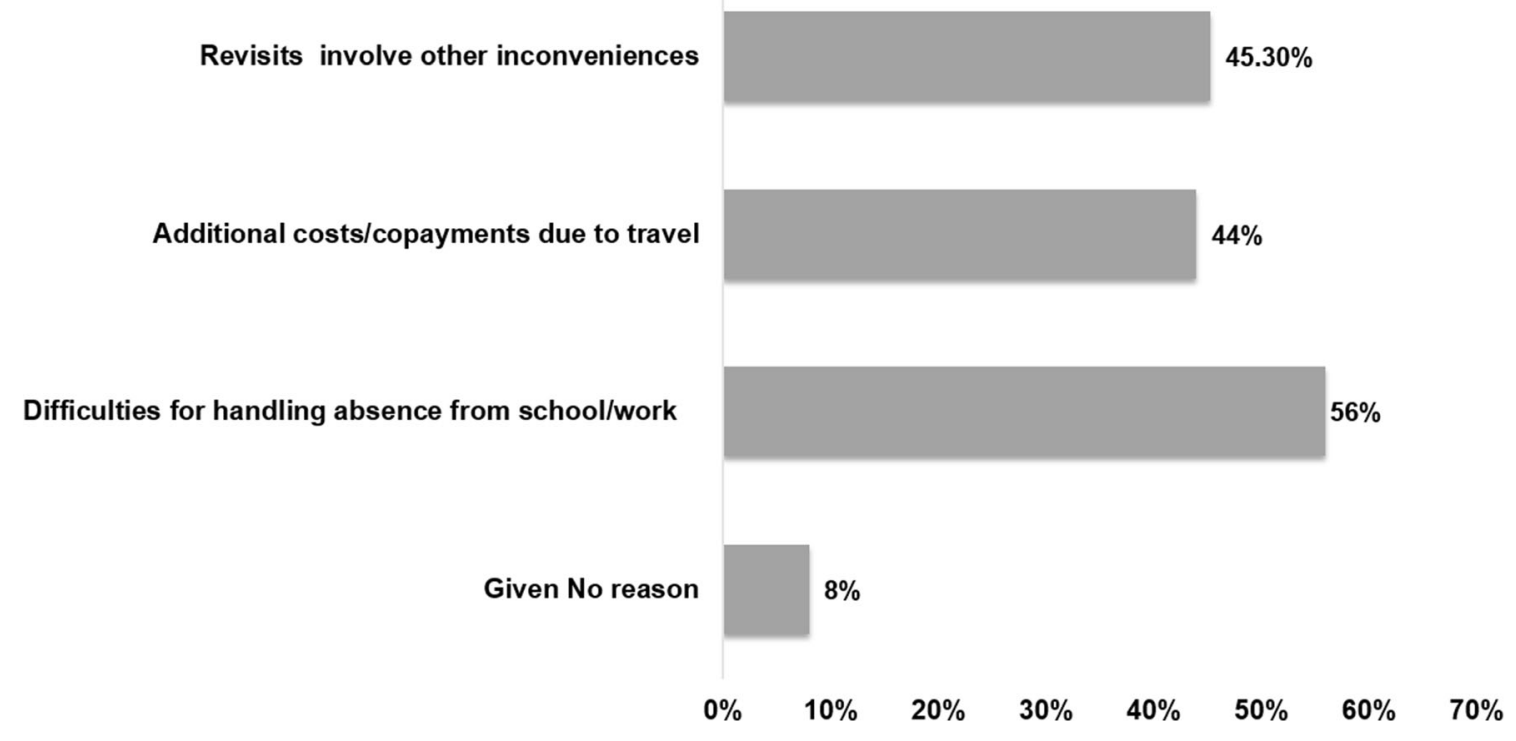

Fig. 1 Most common reasons for not performing traditional HbAlc tests in the laboratory. Patients may have one or more reasons for not performing traditional HbAlc tests in the laboratory

$78.7 \%$ of patients responded that doctors behaved amicably and courteously in the interpersonal manner domain. Also, in the communication domain, about $78 \%$ of the participants responded that the doctors were efficient in explaining the medical tests and not ignoring their questions. At the same time, about $69 \%$ of patients were financially satisfied because they had not to pay more for their medical care. In the time spent with doctors domain, most of the patients $(82 \%)$ reported that their doctors usually spent enough time during the medical follow-up visits. In terms of accessibility and convenience, about $77 \%$ of patients agreed that it was easy to get an appointment for follow-up or consultation. The detailed mean scores of each domain are presented in Table 4. Satisfaction in seven dimensions of the PSQ-18 by gender, type of diabetes, and place of residence is displayed in Table S3 in the supplementary material.

The levels of agreement on each of the eight statements of the HbA1c-POCT satisfaction questionnaire are provided in Table 5. Higher levels of agreement and satisfaction were obtained in the questionnaire areas of collection process, confidence in the process, confidence in the results, convenience/travel, cost, and disease management. The following statements revealed a higher score of agreement: I would rather have blood taken by finger prick than by needle in my arm (mean score $=8.9 \pm$ 1.1). Having immediate feedback on the test result was important as it allowed me to discuss the management with my physician (mean score $=8.7 \pm 1.2$ ), and outside pathology laboratories involve extra time and transport costs (mean score $=8.4 \pm 1.4$ ). A lower level of agreement was obtained for the statement that laboratories have better hygiene processes than POCT (mean score $=2.8 \pm 1.2$ ).

\section{DISCUSSION}

This work is the first in the MENA region to explore diabetic patient satisfaction with $\mathrm{HbA1c}$ on-site POCT and its effect on glycemic control. Our results showed that the implementation of on-site POCT service improved patient compliance to the requested $\mathrm{HbA1c}$ tests in most of the included patients. We also reported a statistically significant reduction in the HbA1c level after POCT service introduction compared to the era of traditional laboratory testing. These results were in agreement with the study 
Table 3 Satisfaction of patients with DM segregated by each item of PSQ-18 questionnaire

\begin{tabular}{|c|c|c|c|c|c|}
\hline Items & & $\begin{array}{l}\text { Not satisfied } \\
\text { (strongly } \\
\text { disagree + disagree) } \\
n(\%)\end{array}$ & $\begin{array}{l}\text { Uncertain } \\
n(\%)\end{array}$ & $\begin{array}{l}\text { Satisfied } \\
\text { (strongly } \\
\text { agree + agree) } \\
n(\%)\end{array}$ & $\begin{array}{l}\text { Mean } \\
\text { score } \\
( \pm S D)\end{array}$ \\
\hline 1 & $\begin{array}{l}\text { Doctors are good about explaining the } \\
\text { reason for medical tests }\end{array}$ & $1(1.3 \%)$ & $11(14.7 \%)$ & $63(84.0 \%)$ & $\begin{array}{l}4.1 \\
\quad( \pm 0.7)\end{array}$ \\
\hline 2 & $\begin{array}{l}\text { I think my doctor's office has everything } \\
\text { needed to provide complete medical care }\end{array}$ & $2(2.7 \%)$ & $7(9.3 \%)$ & $66(88.0 \%)$ & $\begin{array}{l}4.1 \\
\quad( \pm 0.6)\end{array}$ \\
\hline 3 & $\begin{array}{l}\text { The medical care I have been receiving is } \\
\text { just about perfect }\end{array}$ & $0(0.0 \%)$ & $4(5.4 \%)$ & $70(94.6 \%)$ & $\begin{array}{l}4.3 \\
( \pm 0.6)\end{array}$ \\
\hline 4 & $\begin{array}{l}\text { Sometimes doctors make me wonder if } \\
\text { their diagnosis is correct }\end{array}$ & $2(2.7 \%)$ & $8(10.7 \%)$ & $65(86.7 \%)$ & $\begin{array}{l}4.3 \\
( \pm 0.8)\end{array}$ \\
\hline 5 & $\begin{array}{l}\text { I feel confident that I can get the medical } \\
\text { care I need without being set back } \\
\text { financially }\end{array}$ & $5(6.7 \%)$ & $20(26.7 \%)$ & $50(66.7 \%)$ & $\begin{array}{l}3.8 \\
( \pm 0.8)\end{array}$ \\
\hline 6 & $\begin{array}{l}\text { When I go for medical care, they are careful } \\
\text { to check everything when treating and } \\
\text { examining me }\end{array}$ & $1(1.3 \%)$ & $4(5.3 \%)$ & $70(93.3 \%)$ & $\begin{array}{l}4.4 \\
( \pm 0.7)\end{array}$ \\
\hline 7 & $\begin{array}{l}\text { I have to pay for more of my medical care } \\
\text { than I can afford }\end{array}$ & $3(4.0 \%)$ & $18(24.0 \%)$ & $54(72.0 \%)$ & $\begin{array}{l}4.1 \\
\quad( \pm 0.9)\end{array}$ \\
\hline 8 & $\begin{array}{l}\text { I have easy access to the medical specialists I } \\
\text { need }\end{array}$ & $3(4.0 \%)$ & $9(12.0 \%)$ & $63(84.0 \%)$ & $\begin{array}{l}4.2 \\
( \pm 0.8)\end{array}$ \\
\hline 9 & $\begin{array}{l}\text { When I get medical care, people have to } \\
\text { wait too long for emergency treatment }\end{array}$ & $6(8.0 \%)$ & $14(18.7 \%)$ & $55(73.3 \%)$ & $\begin{array}{l}4.0 \\
( \pm 0.9)\end{array}$ \\
\hline 10 & $\begin{array}{l}\text { Doctors act too business-like and } \\
\text { impersonal towards me }\end{array}$ & $5(6.7 \%)$ & $18(24.0 \%)$ & $52(69.3 \%)$ & $\begin{array}{l}4.0 \\
( \pm 0.9)\end{array}$ \\
\hline 11 & $\begin{array}{l}\text { My doctors treat me in a very friendly and } \\
\text { courteous manner }\end{array}$ & $0(0.0 \%)$ & $9(12.0 \%)$ & $66(88.0 \%)$ & $\begin{array}{l}4.1 \\
\quad( \pm 0.6)\end{array}$ \\
\hline 12 & $\begin{array}{l}\text { Those who provide my medical care } \\
\text { sometimes hurry too much when they } \\
\text { treat me }\end{array}$ & $2(2.7 \%)$ & $13(17.3 \%)$ & $60(80.0 \%)$ & $\begin{array}{l}4.1 \\
\quad( \pm 0.8)\end{array}$ \\
\hline 13 & Doctors sometimes ignore what I tell them & $6(8.0 \%)$ & $15(20.0 \%)$ & $54(72.0 \%)$ & $\begin{array}{l}4.1 \\
\quad( \pm 1.0)\end{array}$ \\
\hline 14 & $\begin{array}{l}\text { I have some doubts about the ability of } \\
\text { doctors who treat me }\end{array}$ & $1(1.3 \%)$ & $11(14.7 \%)$ & $63(84.0 \%)$ & $\begin{array}{l}4.4 \\
\quad( \pm 0.8)\end{array}$ \\
\hline 15 & $\begin{array}{l}\text { Doctors usually spend plenty of time with } \\
\text { me }\end{array}$ & $4(5.3 \%)$ & $8(10.7 \%)$ & $63(84.0 \%)$ & $\begin{array}{l}4.0 \\
( \pm 0.8)\end{array}$ \\
\hline 16 & $\begin{array}{l}\text { I find it hard to get an appointment for } \\
\text { medical care right away }\end{array}$ & $13(17.3 \%)$ & $14(18.7 \%)$ & $48(64.0 \%)$ & $\begin{array}{l}3.7 \\
\quad( \pm 1.0)\end{array}$ \\
\hline
\end{tabular}


Table 3 continued

\begin{tabular}{|c|c|c|c|c|c|}
\hline$\overline{\text { Items }}$ & & $\begin{array}{l}\text { Not satisfied } \\
\text { (strongly } \\
\text { disagree + disagree) } \\
n(\%)\end{array}$ & $\begin{array}{l}\text { Uncertain } \\
n(\%)\end{array}$ & $\begin{array}{l}\text { Satisfied } \\
\text { (strongly } \\
\text { agree }+ \text { agree) } \\
n(\%)\end{array}$ & $\begin{array}{l}\text { Mean } \\
\text { score } \\
( \pm \text { SD })\end{array}$ \\
\hline 17 & $\begin{array}{l}\text { I am dissatisfied with some things about the } \\
\text { medical care I receive }\end{array}$ & $4(5.3 \%)$ & $12(16.0 \%)$ & $59(78.7 \%)$ & $\begin{array}{l}4.2 \\
( \pm 0.9)\end{array}$ \\
\hline 18 & $\begin{array}{l}\text { I am able to get medical care whenever I } \\
\text { need it }\end{array}$ & $2(2.7 \%)$ & $8(10.7 \%)$ & $65(86.7 \%)$ & $\begin{array}{l}4.0 \\
( \pm 0.6)\end{array}$ \\
\hline
\end{tabular}

According to the guidelines of the patient satisfaction questionnaire (PSQ-18), (a) For items 1-3, 5, 6, 8, 11, 15, and 18: satisfied is represented by "strongly agree" or "agree"; not satisfied is represented by "strongly disagree" or "disagree". (b) For items $4,7,9,10,12-14,16$, and 17: satisfied is represented by "strongly disagree" or "disagree"; not satisfied is represented by "strongly agree" or "agree". For all items, the score ranges from 1 (strongly dissatisfied) to 5 (strongly satisfied). The higher the score, the higher satisfaction level

Table 4 Satisfaction in seven dimensions of the PSQ-18 satisfaction questionnaire

\begin{tabular}{llll}
\hline Dimension & $\begin{array}{l}\text { Mean score } \\
( \pm \text { SD) }\end{array}$ & $\begin{array}{l}\text { Median score } \\
\text { (range) }\end{array}$ & $\begin{array}{l}\text { \% Satisfied (average of \% } \\
\text { satisfaction of items } \\
\text { of each dimension) (\%) }\end{array}$ \\
\hline General satisfaction (item 3+17) & $8.4( \pm 1.2)$ & $9(5-10)$ & 86.7 \\
Technical quality (item 2 $+4+6+14)$ & $17.2( \pm 1.6)$ & $17(13-20)$ & 88.0 \\
Interpersonal manner (item 10+11) & $8.1( \pm 1.1)$ & $8(6-10)$ & 78.7 \\
Communication (item 1 + 13) & $8.3( \pm 1.3)$ & $8(5-10)$ & 78.0 \\
Financial aspects (item 5 + 7) & $7.9( \pm 1.3)$ & $8(5-10)$ & 69.4 \\
Time spent with doctor (item 12 +15$)$ & $8.1( \pm 1.0)$ & $8(5-10)$ & 82.0 \\
Accessibility and convenience (item $8+9+16+18)$ & $15.9( \pm 1.8$ & $16(11-20)$ & 77.0 \\
\hline
\end{tabular}

PSQ-18 patient satisfaction questionnaire short form

conducted in the Stark Diabetes Center at the University of Texas by Petersen et al., 2007. They reported that, within 6 months of POCT implementation, the average HbA1c for patients seen in the Stark Diabetes Center significantly improved and continued to decrease over time till the end of the study (compared to another center without POCT service) [28]. Furthermore, the recent US primary-care quality improvement study showed that testing the HbA1c using POCT was 3.7 times less likely to miss HbA1c testing during the visit compared to practices that did not have POCT [19].

Further studies have demonstrated the beneficial effect of POCT for HbA1c testing for improving diabetes management and glycemic control. In a US trial with 597 people with T2DM visiting the primary care clinic, rapid availability of HbA1c results was associated with a decrease in the HbA1c level and improved the 
Table 5 Summary of on-site HbAlc point-of-care testing satisfaction questionnaire

\begin{tabular}{|c|c|c|c|}
\hline Areas & Statements & $\begin{array}{l}\text { Mean score } \\
( \pm \text { SD })\end{array}$ & $\begin{array}{l}\text { Median } \\
\text { score } \\
\text { (range) }\end{array}$ \\
\hline $\begin{array}{l}\text { Collection } \\
\text { process }\end{array}$ & I would rather have blood taken by finger rick than by needle in my arm & $8.9( \pm 1.1)$ & $9(6.0-10)$ \\
\hline $\begin{array}{l}\text { Confidence in } \\
\text { the process }\end{array}$ & Laboratories have better hygiene processes than point-of-care testing & $2.8( \pm 2.1)$ & $2(0.0-8)$ \\
\hline $\begin{array}{l}\text { Confidence in } \\
\text { the results }\end{array}$ & $\begin{array}{l}\text { I have confidence in the information given the results by my physician or } \\
\text { practice regarding my on-site point-of-care HbAlc\% test result }\end{array}$ & $8.2( \pm 1.4)$ & $8(5.0-10)$ \\
\hline Convenience & Not having to travel to an outside laboratory would be convenient & $8.3( \pm 1.4)$ & $9(4.0-10)$ \\
\hline Cost & Outside pathology laboratories involve extra time and transport costs & $8.4( \pm 1.4)$ & $9(5.0-10)$ \\
\hline \multirow[t]{3}{*}{$\begin{array}{l}\text { Disease } \\
\text { management }\end{array}$} & $\begin{array}{l}\text { Having immediate feedback on the test result for my condition was } \\
\text { important as it allowed/would allow me to discuss the management of } \\
\text { my condition with my physician }\end{array}$ & $8.7( \pm 1.2)$ & $9(6.0-10)$ \\
\hline & $\begin{array}{l}\text { I am/would be more motivated to look after my condition because of } \\
\text { regular on-site point-of-care HbA1c\% testing }\end{array}$ & $7.6( \pm 1.7)$ & $8(4.0-10)$ \\
\hline & $\begin{array}{l}\text { On-site } \mathrm{HbAlc} \% \text { point-of care-testing strengthened/would strengthen my } \\
\text { relationship with my physician }\end{array}$ & $7.6( \pm 1.7)$ & $8(3.0-10)$ \\
\hline
\end{tabular}

The score ranges from 0 (completely disagree) to 10 (completely agree) for all statements. The higher the score the higher satisfaction level

frequency of DM treatment intensification [29]. As the authors emphasize, having HbA1c test results available quickly allows for the identification of patients with diabetes with adequate metabolic and glycemic control and, as a result, reduces the risk of hypoglycemia from improper therapy escalation. On the other hand, in the UK cohort feasibility study, Hirst and colleagues did not report any significant difference in $\mathrm{HbA} 1 \mathrm{c}$ at the end of the study compared with the baseline value, which was justified by the small sample size [17].

To evaluate the potential effects of on-site POC for HbA1c testing in a primary care setting, data by Sølvik et al. were collected 3 months and 6 months before POCT implementation, and the same after POCT implementation. Authors reported that a high level of adherence to guideline-compliant HbA1c testing frequency by healthcare providers increased from $68.3 \%$ and $65.9 \%$ (3 months and 6 months before implementation) to $82.9 \%$ and $95 \%$ (3 months and 6 months after implementation) [30]. These data were in agreement with our results, in which we observed that a higher level of adherence to guideline-compliant HbA1c testing frequency by physicians or diabetic educators increased from 24\% (12 months before POCT implementation) to $85 \%$ (12 months after POCT implementation). As stated by the ADA, the implementation of POCT for HbA1c testing provides an opportunity for more timely treatment modifications for patients with non-controlled diabetes [31]. The prompt handling of $\mathrm{HbA} 1 \mathrm{c}$ results provided by the POCT avoids the patient with diabetes being affected by the turnaround time consumed by the laboratory service for testing and reporting [8]. This delay can affect the proper timing of intensification/modification of the treatment plan and reduce patient adherence to medical therapy [8]. Besides, good glycemic 
control is a substantial step to delay or prevent complications and end-organ damage associated with diabetes [32].

Further to the positive impact of the POCT on glycemic control, it also reports an increased patient satisfaction towards the provided healthcare services. In the present study, patients showed a high level of satisfaction on the seven dimensions of the PSQ-18 questionnaire towards the provided healthcare services at the Diabetes Treatment Centre of PSMMC after POCT implementation for HbA1c testing. Patient gender, type of diabetes, and place of residence (in Riyadh, the capital city, or outside Riyadh) did not affect the level of satisfaction among the included patients. Patients with diabetes also showed high levels of agreement and satisfaction on the HbA1c-POCT satisfaction questionnaire.

The results of a large randomized controlled trial assessing the extent of POCT in Australian medical practices showed that patients randomized to POCT reported a higher level of satisfaction and more confidence in the medical process and enhancement in patient relationship with their physician [20]. The prompt availability of $\mathrm{HbA} 1 \mathrm{c}$ results permits face-to-face discussion between doctor and patient, thus improving patient-doctor communication, the decision-making process, and overall patient satisfaction [33]. Furthermore, lower patient revisits linked to POCT implementation may also contribute to higher patient satisfaction. Implementation of POC testing has been shown to reduce patient revisits by up to $61 \%$ [34]. From an economic perspective, the UK National Health Service estimated the costs for diabetes treatment around $£ 13.8$ billion/year, while in the USA, the national expenditure on diabetes care in 2013 was US $\$ 548$ billion [17]. The health expenditure on diabetes was estimated to be US $\$ 20.5$ billion across the MENA region in 2017, and interestingly, it is anticipated to reach US $\$ 37.1$ billion by 2045 [35]. As per the 2017 IDF published data, KSA was ranked as the highest amongst the MENA countries in terms of health expenditure on diabetes with $\$ 13.1$ billion (international dollars) [35]. Although the unit of POCT costs more than the conventional laboratory testing, the total reduction in the financial burden associated with POCT (including patient revisits, travel costs, work absence, and time saved) will reduce healthcare costs more than the laboratory testing [36]. According to a recently published German study [37], implementing POC for HbA1c testing in diabetes practices can enhance office processes and increase physician, staff, and patient satisfaction. It demonstrates a significant acceleration of evaluation processes as a result of fewer time-consuming blood samples, scheduling activities, and patient visits.

Despite the significant benefits of POCT for HbA1c testing on glycemic control and patient satisfaction in patients with diabetes, the ADA has yet to recommend POCT for the detection of prediabetes or diabetes diagnosis. Therefore, future studies should emphasize the impact of POCT on prediabetes or diabetes diagnosis. Furthermore, maintaining a balance between the advantages and disadvantages of HbA1c tests and a sustained emphasis on accuracy and cost-effectiveness will promote the usage of POCT for HbA1c testing in the treatment plan and diagnosis of patients with diabetes/prediabetes. Furthermore, maintaining the balance between the benefits and harms associated with tests, the multiple attributes of POC tests, and a continued emphasis on accuracy and cost-effectiveness will increase the use of POCT for $\mathrm{HbA} 1 \mathrm{c}$ testing in the treatment and diagnosis of patients with diabetes/prediabetes [8].

The impact of POCT on glycemic control and patient satisfaction in patients with diabetes in Saudi Arabia is uncertain, and this study contributes valuable data on the use of POCT. However, our study was limited by the relatively small sample size of patients from a single site that might limit the generalizability of the study results. Moreover, we did not assess the physician satisfaction with regard to the implementation of POCT in their clinic. Therefore, a larger multicenter study is warranted to inform future health policy. Additionally, because of the nature of this study, we cannot collect the patient satisfaction data retrospectively; therefore, changes in the level of satisfaction before and after the POCT service implementation cannot be determined. Also, we did not collect the diabetes-related 
complications among our study population because that was beyond the scope of our study.

\section{CONCLUSIONS}

HbA1c testing at POCT improved adherence to recommendations for HbA1c testing frequency for better glycemic control and higher patient satisfaction. POCT reduces turnaround time, improves glycemic control, and facilitates/ quickens the decision-making process. HbA1c measurement with POC devices is recommended to be implemented in primary care centers. All of the described benefits of POCT come together to make HbA1c testing the most common procedure for diabetes management at the point of care. Continued research of accuracy improvements and cost-effectiveness analysis of various POCT systems will increase the development of these POC testing systems as the techniques of choice for HbA1c testing in everyday practice in the diabetic treatment centers.

\section{ACKNOWLEDGEMENTS}

The authors thank the study participants for their participation.

Funding. No funding or sponsorship was received for this study or publication of this article. The Rapid Service Fee was funded by the authors.

Authorship. All named authors meet the International Committee of Medical Journal Editors (ICMJE) criteria for authorship for this article, take responsibility for the integrity of the work as a whole, and have given their approval for this version to be published.

Author Contributions. All authors contributed to the study conception and design. Material preparation, data collection and analysis were performed by all authors. The first draft of the manuscript was written by AAA and all authors commented on previous versions of the manuscript. All authors read and approved the final manuscript.

Medical Writing Assistance. Medical writing assistance in the preparation of this article was provided by Dr. Hussien Ahmed MD, MS, Ph.D.(c) of RAY-CRO.

Disclosures. Ayman Abdullah Al Hayek, Wael Mohammed Alzahrani, Abdulghani Habib Al Saeed and Mohammed Abdulaziz Aldawish have nothing to disclose.

Compliance with Ethics Guidelines. The protocols and the subject information/informed consent forms were reviewed and approved by the Research and Ethics Committee of PSMMC (IRB approval No. 1486). Our study was performed in accordance with the Helsinki Declaration of 1964, and its later amendments. All participants provided oral and written informed consent before completing the study measurement. For patients 18 years of age or younger, verbal consent from the patients and written informed consent from their parents/caregivers were obtained.

Data Availability. The datasets generated during and/or analyzed during the current study are available from the corresponding author on reasonable request.

Open Access. This article is licensed under a Creative Commons Attribution-NonCommercial 4.0 International License, which permits any non-commercial use, sharing, adaptation, distribution and reproduction in any medium or format, as long as you give appropriate credit to the original author(s) and the source, provide a link to the Creative Commons licence, and indicate if changes were made. The images or other third party material in this article are included in the article's Creative Commons licence, unless indicated otherwise in a credit line to the material. If material is not included in the article's Creative Commons licence and your intended use is not permitted by statutory regulation or exceeds the permitted use, you will need to obtain permission directly from the copyright holder. To view a copy of this licence, 
visit http://creativecommons.org/licenses/by$\mathrm{nc} / 4.0 /$.

\section{REFERENCES}

1. Al-Lawati JA. Diabetes mellitus: a local and global public health emergency! Oman Med J. 2017;32: 177-9. https://doi.org/10.5001/omj.2017.34.

2. Patterson CC, Harjutsalo V, Rosenbauer J, et al. Trends and cyclical variation in the incidence of childhood type 1 diabetes in 26 European centres in the 25 year period 1989-2013: a multicentre prospective registration study. Diabetologia. 2019;62:408-17. https://doi.org/10.1007/s00125018-4763-3.

3. Wang L, Gao P, Zhang M, et al. Prevalence and ethnic pattern of diabetes and prediabetes in China in 2013. J Am Med Assoc. 2017;317:2515-23. https://doi.org/10.1001/jama.2017.7596.

4. Dwyer-Lindgren L, Mackenbach JP, Van Lenthe FJ, Flaxman AD, Mokdad AH. Diagnosed and undiagnosed diabetes prevalence by county in the US 1999-2012. Diabetes Care. 2016;39:1556-62. https://doi.org/10.2337/dc16-0678.

5. Saeedi P, Petersohn I, Salpea P, et al. Global and regional diabetes prevalence estimates for 2019 and projections for 2030 and 2045: results from the International Diabetes Federation Diabetes Atlas, 9th edition. Diabetes Res Clin Pract. 2019;157: 107843. https://doi.org/10.1016/j.diabres.2019. 107843.

6. World Health Organization. Saudi Arabia - Diabetes country profile. 2016. https://www.who.int/ diabetes/country-profiles/sau_en.pdf. Accessed 4 Jun 2021.

7. American Diabetes Association. Glycemic targets: standards of medical care in diabetes-2021. Diabetes Care. 2021;44:S73-84. https://doi.org/10. 2337/dc21-S006.

8. Schnell O, Crocker JB, Weng J. Impact of HbA1c testing at point of care on diabetes management. J Diabetes Sci Technol. 2017;11:611-7. https://doi. org/10.1177/1932296816678263.

9. Lian J, Liang Y. Diabetes management in the real world and the impact of adherence to guideline recommendations. Curr Med Res Opin. 2014;30: 2233-40. https://doi.org/10.1185/03007995.2014. 952716.
10. Ali MK, Bullard KMK, Gregg EW, Del Rio C. A cascade of care for diabetes in the United States: visualizing the gaps. Ann Intern Med. 2014;161:681-9. https://doi.org/10.7326/M14-0019.

11. Blaslov K, Naranđa FS, Kruljac I, Renar IP. Treatment approach to type 2 diabetes: past, present and future. World J Diabetes. 2018;9:209-19. https:// doi.org/10.4239/wjd.v9.i12.209.

12. Silver B, Ramaiya $\mathrm{K}$, Andrew SB, et al. EADSG guidelines: insulin therapy in diabetes. Diabetes Ther. 2018;9:449-92. https://doi.org/10.1007/ s13300-018-0384-6.

13. Inzucchi SE, Bergenstal RM, Buse JB, et al. Management of hyperglycemia in type 2 diabetes, 2015: a patient-centered approach: update to a position statement of the American Diabetes Association and the European Association for the Study of Diabetes. Diabetes Care. 2015;38:140-9. https://doi. org/10.2337/dc14-2441.

14. LeBlanc ES, Rosales AG, Kachroo S, et al. Provider beliefs about diabetes treatment have little impact on glycemic control of their patients with diabetes. BMJ Open Diabetes Res Care. 2015;3: e000062. https://doi.org/10.1136/bmjdrc-2014-000062.

15. Brown JB, Harris SB, Webster-Bogaert S, Porter S. Point-of-care testing in diabetes management: what role does it play? Diabetes Spectr. 2004;17:244-8. https://doi.org/10.2337/diaspect.17.4.244.

16. Hobbs R. Near patient testing in primary care. BMJ. 1996;312:263-4. https://doi.org/10.1136/bmj.312. 7026.263 .

17. Hirst JA, Stevens RJ, Smith I, James T, Gudgin BC, Farmer AJ. How can point-of-care HbA1c testing be integrated into UK primary care consultations? A feasibility study. Diabetes Res Clin Pract. 2017;130: 113-20. https://doi.org/10.1016/j.diabres.2017.05. 014.

18. Egbunike V, Gerard S. The impact of point-of-care A1C testing on provider compliance and A1C levels in a primary setting. Diabetes Educ. 2013;39:66-73. https://doi.org/10.1177/0145721712465340.

19. Crocker JB, Lynch SH, Guarino AJ, Lewandrowski K. The impact of point-of-care hemoglobin A1c testing on population health-based onsite testing adherence: a primary-care quality improvement study. J Diabetes Sci Technol. 2021;15:561-7. https://doi. org/10.1177/1932296820972751.

20. Laurence CO, Gialamas A, Bubner T, et al. Patient satisfaction with point-of-care testing in general practice. Br J Gen Pract. 2010;60:e98-104. https:// doi.org/10.3399/bjgp10X483508. 
21. Agarwal P, Biswas R. Satisfaction of patients attending a rural hospital of Darjeeling district in West Bengal, India. Int J Community Med Public Heal. 2017;4:1932. https://doi.org/10.18203/23946040.ijcmph20172152.

22. Crocker B, Lewandrowski E-L, Lewandrowski N, Gregory K, Lewandrowski K. Patient satisfaction with point-of-care laboratory testing: report of a quality improvement program in an ambulatory practice of an academic medical center. Clin Chim Acta. 2013;424:8-11. https://doi.org/10.1016/j.cca. 2013.04.025.

23. Hirst JA, Farmer AJ, Williams V. How point-of-care HbA1c testing changes the behaviour of people with diabetes and clinicians: a qualitative study. Diabet Med. 2020;37:1008-15. https://doi.org/10. 1111/dme.14219.

24. Hirst JA, McLellan JH, Price CP, et al. Performance of point-of-care HbA1c test devices: implications for use in clinical practice: a systematic review and meta-analysis. Clin Chem Lab Med. 2017. https:// doi.org/10.1515/cclm-2016-0303.

25. Imrit C, Neergheen-Bhujun VS, Joonas N. Evaluation of the Roche Cobas b 101 glycosylated hemoglobin point-of-care analyzer. Point Care J NearPatient Test Technol. 2017;16:135-7. https://doi. org/10.1097/POC.0000000000000142.

26. Marshall GN, Hays RD, Sherbourne CD, Wells KB. The structure of patient satisfaction with outpatient medical care. Psychol Assess. 1993;5:477-83. https://doi.org/10.1037/1040-3590.5.4.477.

27. Patient Satisfaction Questionnaire from RAND Health Care. RAND. https://www.rand.org/healthcare/surveys_tools/psq.html. Accessed 5 Aug 2021.

28. Petersen JR, Finley JB, Okorodudu AO, Mohammad AA, Grady JJ, Bajaj M. Effect of point-of-care on maintenance of glycemic control as measured by A1C. Diabetes Care. 2007;30:713-5. https://doi.org/ 10.2337/dc06-1909.

29. Miller CD, Barnes CS, Phillips LS, et al. Rapid A1c availability improves clinical decision-making in an urban primary care clinic. Diabetes Care. 2003;26:
1158-63. https://doi.org/10.2337/diacare.26.4. 1158.

30. Sølvik UØ, Røraas T, Christensen NG, Sandberg S. Diagnosing diabetes mellitus: performance of hemoglobin A1c point-of-care instruments in general practice offices. Clin Chem. 2013;59:1790-801. https://doi.org/10.1373/clinchem.2013.210781.

31. American Diabetes Association. Standards of medical care in diabetes-2016. Diabetes Care 2016. https://care.diabetesjournals.org/content/suppl/ 2015/12/21/39.Supplement_1.DC2/2016Standards-of-Care.pdf. Accessed 3 June 2021.

32. Fasil A, Biadgo B, Abebe M. Glycemic control and diabetes complications among diabetes mellitus patients attending at University of Gondar Hospital, Northwest Ethiopia. Diabetes Metab Syndr Obes Targets Ther. 2019;12:75-83. https://doi.org/10. 2147/DMSO.S185614.

33. Belle J, Belle Brown J, Harris SB, Webster-Bogaert S, Porter S. Point-of-care testing in diabetes management: what role does it play? Diabetes Spectr. 2004;17:244-9.

34. Crocker JB, Lee-Lewandrowski E, Lewandrowski N, Baron J, Gregory K, Lewandrowski K. Implementation of point-of-care testing in an ambulatory practice of an academic medical center. Am J Clin Pathol. 2014;142:640-6. https://doi.org/10.1309/ AJCPYK1KV2KBCDDL.

35. Fernandes da R, Huang Y, Karuranga S, Malanda B, Cho N, Ohlrogge A. Health expenditure on diabetes in the middle east and North Africa region in 2017. Int Diabetes Fed. 2017;3905.

36. Grieve R, Beech R, Vincent J, Mazurkiewicz J. Near patient testing in diabetes clinics: appraising the costs and outcomes. Health Technol Assess (Rockv). 1999. https://doi.org/10.3310/hta3150.

37. Patzer K-H, Ardjomand P, Göhring K, et al. Implementation of HbA1c point of care testing in 3 German medical practices: impact on workflow and physician, staff, and patient satisfaction. J Diabetes Sci Technol. 2018;12:687-94. https://doi.org/10. $1177 / 1932296818759690$. 